Artigo

\title{
Governabilidade, governança e poder informal Um problema central de sociologia política
}

\author{
Governability, governance and informal power \\ A central problem of political sociology
}

Roberto Dutra Torres*

\begin{abstract}
Resumo: O artigo é de natureza eminentemente teórica e busca relacionar o conceito de governança com os problemas estruturais de governabilidade que afetam o estado moderno. A crise de governabilidade, pensada em seu significado sociológico mais amplo como dependência estrutural do estado de dinâmicas sociais que não podem ser controladas pelo poder político formal, é tomada como referência social a partir da qual a noção de governança vai se desenvolver. A tese central é a de que esta noção, assim como os diversos significados a ela associados, está constitutivamente ligada às tentativas e pretensões de normatizar as relações de poder informais que se estabelecem entre o estado e a sociedade civil.
\end{abstract}

Palavras-chave: Governança. Governabilidade. Poder formal. Poder informal.

Abstract: The article is a theoretical work and seeks to relate the concept of governance with the structural problems of governability that affect the modern state. The crisis of governability, considered in its broader sociological significance as structural dependence of the state of social dynamics that cannot be controlled by formal political power, is taken as the social reference from which the notion of governance will be developed. The central thesis is that this notion, as well as the various meanings associated with it, is constitutively bound to the pretensions and attempts to regulate the informal power relationships that are established between the state and civil society.

Keywords: Governance. Governability. Formal power. Informal power.

\footnotetext{
* Doutor em Sociologia pela Humboldt Universität zu Berlin (Alemanha), professor da Universidade Estadual do Norte Fluminense Darcy Ribeiro (Uenf) em Campos de Goytacazes, RJ, e Diretor de Estudos e Políticas do Estado, das Instituições e da Democracia do Instituto de Pesquisa Econômica Aplicada em Brasília, DF, Brasil<roberto.torres@ipea.gov.br>. Temas de interesse: teoria social, sociologia da estratificação social, sociologia da religião, teoria do reconhecimento social, teoria da modernidade, teoria dos sistemas, sociologia da administração pública.
}

Civitas, Porto Alegre, v. 16 , n. 1, p. 153-171, jan.-mar. 2016 


\section{Introdução}

A partir do começo dos anos 1970 os países do Atlântico Norte vivenciaram um longo período de crise em suas instituições políticas. Trata-se de uma crise do estado moderno, que veio a afetar especialmente suas relações com a sociedade. Nos países da periferia do Atlântico Norte, sobretudo na América Latina, esta crise teve enormes efeitos negativos sobre o estado nacional-desenvolvimentista, desafiando e contradizendo as expectativas de que o estado fosse capaz de organizar ou mesmo de ditar os rumos do desenvolvimento econômico e social.

Seja na teoria política, seja na esfera pública mais ampla, esta crise do estado foi diagnosticada a partir de três aspectos gerais: a crise fiscal, a crise de legitimidade e a crise administrativa do estado. Estas três dimensões da crise demonstram claramente que o centro da questão são as relações do estado com a sociedade. No primeiro caso, o problema tem a ver com a capacidade do sistema político de financiar suas atividades, ou seja, afeta sua relação com o sistema econômico; no segundo, o foco recai sobre a capacidade dos atores e organizações do sistema político de produzir e manter a lealdade do público de cidadãos em suas diversas clivagens de interesses, expectativas, visões de mundo e valores; no terceiro caso, o problema é a capacidade do estado, especialmente de seu braço administrativo, de conduzir o processo de implementação de políticas públicas, entre outras coisas em função de crescente complexidade das redes de atores e organizações que afetam a execução das decisões políticas e impedem, em grande medida, uma convergência segura entre a formulação de políticas públicas e os resultados obtidos em sua implementação.

No que se refere a esta dimensão da crise administrativa, é interessante destacar que os diferentes modelos teóricos criados para explicar os impasses da fase de implementação de políticas públicas têm em comum o desafio de explicar (e não raro propor estratégias de intervenção) os fracassos e dificuldades dos agentes governamentais e da administração pública em conduzir a fase de implementação (Hudson e Lowe, 2004, p. 205). E a evolução analítica daí decorrente pode ser entendida como um crescente distanciamento (apesar das tentativas de síntese) em relação ao paradigma top-down, cuja ênfase está justamente na capacidade dos agentes da administração pública em emanarem diretrizes claras e controlarem a ação dos atores e instituições envolvidos na fase de implementação.

Os conceitos de governabilidade e governança são parte indissociável das reflexões em torno destes aspectos constitutivos da crise. Englobam, 
portanto, as dimensões da crise fiscal, da crise de legitimidade e da crise administrativa. Neste texto, propomos reconstruir as linhas gerais de como estes dois conceitos foram definidos e usados, para depois averiguar sua empregabilidade, assim como as possibilidades de "fusão" ou combinação entre eles, em relação a problemas concretos envolvendo a relação entre estado e sociedade.

\section{Os diagnósticos sobre a crise de governabilidade}

As três dimensões da crise do estado mencionadas acima aparecem de forma bem nítida nos diagnósticos sobre a crise de governabilidade do estado. Em sua maioria, os diagnósticos priorizam uma destas dimensões. Alguns outros, porém, tentam combiná-las. O diagnóstico sobre a crise fiscal (O’Connor, 1997) entende que a crescente incapacidade do estado em resolver problemas colocados pela sociedade (crise de governabilidade) resulta essencialmente dos impasses que encontra para financiar a expansão de atividades e serviços demandados pelos cidadãos. Segundo este diagnóstico, a cadeia causal começa pela sobrecarga de problemas e demandas sociais que levam ao crescimento da intervenção estatal e, consequentemente, à necessidade de aumentar a arrecadação para financiar as atividades e serviços estatais. Ou seja, embora o problema afete diretamente a relação entre estado e economia, ele surgiria dentro do sistema político, sendo primariamente uma questão de inflação das demandas sociais endereçadas ao sistema político. A terapia daí deduzida consiste em reduzir as expectativas e demandas dos diferentes grupos e setores sociais em relação ao estado como meio para diminuir as atividades e os gastos governamentais. Em resumo, a crise é percebida não como a crise do estado em geral, mas sim como a crise de uma forma particular de estado: o estado interventor de bem-estar social. No debate brasileiro atual, este diagnóstico da crise fiscal domina o discurso sobre a crise econômica e política. Com o apoio e encorajamentos decisivos das linhas editoriais e opinativas dos principais veículos de comunicação eletrônicos e impressos do país, economistas liberais (como Armínio Fraga e Samuel Pessoa) ${ }^{1}$ vêm na crise do governo Dilma oportunidade ideal para colocar a agenda - em tom mais ou menos radical - de redução estrutural do gasto social, sob o argumento de que nosso incipiente "estado de bem-estar social não cabe no PIB". Trata-se, evidentemente, do ponto de vista sociológico, não de um diagnóstico científico neutro, mas sim de um discurso de economia

\footnotetext{
${ }^{1}$ Ver <http://www.institutomillenium.org.br/artigos/acompanhamento-contrato-social-2/> e $<\mathrm{http}$ ://opiniao.estadao.com.br/noticias/geral,respostas-a—altura-da-crise,1761085>.
} 
política que busca orientar a política negando seu caráter político, buscando afirmar-se como uma visão puramente técnica. ${ }^{2}$

O diagnóstico sobre a crise de legitimidade concorda com a existência de uma crise fiscal do estado; mas sua ênfase recai sobre o crescente déficit de legitimidade das atividades governamentais. A principal razão deste déficit de legitimidade do sistema político seria a combinação entre o crescimento da participação política, ocorrida sobretudo a partir dos anos 1960, e a diminuição da confiança pública nas autoridades e instituições políticas, claramente identificável nos anos 1970. Enquanto o aumento da participação, ao trazer mais problemas e demandas sociais para o sistema, gera um crescimento da atividade governamental, a diminuição da confiança nas instituições e autoridades enfraquece a capacidade do estado de resolver problemas e atender demandas. O resultado é uma crise de governabilidade que se retroalimenta em espiral: mais problemas e demandas e menos legitimidade das instituições responsáveis por atendê-los, logo problemas e demandas não atendidos que irão corroer ainda mais a legitimidade e a governabilidade do estado. A terapia, muito parecida com aquela recomendada para enfrentar a crise fiscal, consiste em, por um lado, "descarregar" o sistema político das muitas demandas sociais e, por outro lado, em descentralizar suas atividades como forma de redistribuir as responsabilidades e os riscos de deslegitimação entre os diversos níveis de governo (Huntington, 1975).

O diagnóstico sobre a crise administrativa tenta, na verdade, combinar os efeitos desta dimensão sobre a atividade estatal com os problemas de legitimidade daí decorrentes. A raiz do problema residiria na crescente incapacidade do estado de controlar e induzir o desenvolvimento econômico. É dizer, na crescente incapacidade do estado de administrar a esfera social que mais fortemente afeta, positiva e negativamente, as demandas por inclusão e integração social. Daí que a crise administrativa quase automaticamente se converte em uma crise de legitimidade da ação do estado: ao tornar-se incapaz de administrar as chances de inclusão e integração social vinculadas ao desenvolvimento econômico o estado perde lealdade popular e portanto legitimidade (Habermas, 2002). Neste diagnóstico, a crise de legitimidade resulta diretamente da crise administrativa, entendida como a crescente incapacidade do sistema político de controlar e dirigir sistemas sociais - especialmente o sistema econômico, mas também o próprio sistema administrativo - que funcionam crescentemente sobre a base de sua racionalidade interna, cada vez

${ }^{2}$ É que o podemos chamar, inventando uma fórmula paradoxal afeita ao objeto, de politica da despolitização da política econômica. Sobre a construção de um senso comum que resulta e ao mesmo tempo reforça esta "política da despolitização" ver o trabalho de Roberto Grün (2013). 
mais desacoplada do mundo vivido e da esfera pública e, com isso, também cada vez mais insensível às demandas, interesses, expectativas, visões de mundo e valores sociais.

Apesar de suas diferenças, tanto em termos de abordagem teórica como em termos de orientação ideológica, os diagnósticos sobre a crise de governabilidade parecem convergir em um aspecto decisivo: o estado, seja por razões fiscais, administrativas ou de legitimidade, ou mesmo pela combinação delas, aparece como cada vez mais incapaz de resolver os problemas e atender as demandas sociais. Na linguagem da velha teoria dos sistemas: o estado releva-se crescentemente incapaz de produzir os "outputs" necessários para gerar e manter a lealdade dos atores, grupos e organizações com seus novos e crescentes "inputs" endereçados ao sistema político.

\section{O conceito de governança e as reformas gerencialistas do estado}

Se o conceito de governabilidade surge como reação semântica à necessidade de diagnósticos e soluções para a crise do estado em dirigir processos sociais e em atender às demandas sociais a ele endereçadas, o conceito de governança refere-se mais fortemente à dimensão normativa da atividade estatal. Em que pese suas possíveis ambiguidades e imprecisões, a noção de governança, seja em seu uso pioneiro pelo Banco Mundial para entender os problemas políticos dos países periféricos seja em seu uso atual, está constitutivamente vinculada à questão das condições de funcionamento do "bom governo", explícita ou implicitamente entendido como "governo democrático".

O uso deste conceito para descrever e entender fenômenos políticos nos remete às preocupações do Banco Mundial com as condições de funcionamento da democracia em países periféricos (ou "em desenvolvimento", se se preferir algum eufemismo). O contexto social e histórico no qual o conceito de governança ganha seu sentido específico é o contexto da perda de plausibilidade da "teoria de modernização", vigente com toda força até o final dos anos 1960, enquanto explicação para as possibilidades de surgimento e manutenção da democracia nestes países que não fazem parte do "seleto grupo" das democracias do Atlântico Norte. Para a "teoria da modernização" o "bom governo" (democracia) seria uma consequência automática do desenvolvimento econômico. O pressuposto não tematizado é o de que a esfera econômica, em seu desenvolvimento nos países mais pobres, possui uma relação de afinidade quase automática com uma determinada forma de organização do sistema político: a democracia representativa como melhor 
formato institucional que garante os direitos de cidadania. Entre os diferentes sistemas sociais, especialmente entre economia, política e direito, haveriam relações necessárias de harmonia e integração, de modo que all good things go togheter. Daí que possíveis tensões, conflitos e desequilíbrios entre desenvolvimento econômico, desenvolvimento político e cidadania sejam ignorados ou negligenciados. Os regimes autoritários na América Latina, para ficar apenas em um exemplo, que tanta afinidade mostraram com o desenvolvimento econômico acelerado, mas pouca ou nenhuma com a garantia dos direitos de cidadania, minaram o poder de convencimento desta concepção etapista da mudança política.

O sentido específico do conceito de governança consiste exatamente no distanciamento que ele marca em relação à "teoria da modernização". Ao enfrentar o problema do inegável desacoplamento entre desenvolvimento econômico e democracia, o conceito de governança lança luz sobre o caráter contingente da relação entre estado e sociedade, evidenciando que as condições do "bom governo" não estão dadas pelo desenvolvimento econômico, devendo ser buscadas nos aspectos institucionais e culturais próprios da vida política. Não se trata aqui de afirmar que este sentido específico está explicitamente contido nas diferentes formulações sobre o conceito de governança. Trata-se antes de identificar o problema central (desenvolvimento econômico não é garantia suficiente de governos democráticos) com o qual o conceito vai se ocupar em sua aplicação aos fenômenos do sistema político. Ou seja, o sentido específico que atribuímos ao conceito refere-se diretamente ao modo como ele foi e é usado na política, e menos ao modo como seus diversos formuladores quiserem defini-lo.

A primazia do uso prático na reconstrução do sentido do conceito de governança - e vale repetir: nossa tese é a de que este uso prático está vinculado ao problema de definir as condições do "bom governo" em um contexto no qual a relação entre desenvolvimento econômico e democracia é crescentemente percebida como contingente - pode ser encontrada de forma coerente na tradição hermenêutica. Como ressalta Schneider (2010), a reconstrução hermenêutica do sentido de qualquer conceito, texto ou artefato cultural consiste em identificar a questão para a qual o conceito, o texto ou o artefato cultural constituem a resposta. ${ }^{3} \mathrm{~A}$ interpretação do material empírico consiste na identificação de relações de sentido como relações entre questões e respostas (Schneider, 2010, p. 221). Na tradição que remonta a Gadamer,

\footnotetext{
${ }^{3}$ Neste sentido, o método hermenêutico se assemelha à análise funcional, tal como formulada por Luhmann, a qual interpreta o material empírico como solução contingente para problemas que admitem soluções alternativas (cf. Schneider, 2010, p. 203-224).
} 
a reconstrução de relações de sentido não se limita à concepção subjetivista que só permite observar o sentido onde ele foi intencionalmente atribuído e articulado. Na verdade, a empreitada mais heurística e desafiadora consiste precisamente em reconstruir relações de sentido cuja existência independe da intenção dos indivíduos, ou seja, como relações genuinamente sociais. Como lembra o próprio Gadamer (1971, p. 70ss): “é possível vivenciar sentido também onde ele não foi produzido de forma intencional". Deste modo, o conceito de governança encontra seu sentido social mais estruturante menos nas definições explicitamente formuladas pelos autores e atores, e mais na questão-problema para a qual ele constitui uma tentativa de resposta: a necessidade de explicar e conceber as condições do "bom governo" (o governo democrático) para além da concepção determinista e etapista da "teoria da modernização" que enxergava o desenvolvimento político como efeito positivo necessário do desenvolvimento econômico.

$\mathrm{Na}$ medida em que a vida política é concebida como relativamente autônoma em relação à economia, a narrativa determinista e etapista tende a ser deslocada por concepções que evidenciam mais fortemente o peso das visões normativas sobre o "bom governo" associadas à dinâmica interna do sistema político. No caso do conceito de governança, como iremos ver mais à frente, as visões normativas parecem estar direcionadas às relações de poder informais que se estabelecem entre o estado e a sociedade civil. Aqui vale ressaltar que o teor normativo do conceito não resulta de sua definição científica, mas de seu uso prático imanente à sociedade, particularmente ao seu sistema político. Daí que a tarefa sociológica consiste em reconstruir este teor normativo como um dos componentes centrais do sentido social prático da categoria de governança, e não em projetar no objeto (no conceito) uma normatividade que lhe é estranha.

No entanto, como o conceito foi e é objeto de um uso inflacionado em diversos contextos (fala-se, para ficar em poucos exemplos, em governança global, governança eleitoral, governança corporativa), torna-se quase impossível livrá-lo de significados polissêmicos, por vezes incompatíveis entre si. E está é a razão pela qual alguns autores (Santos, 1997) defendem uma fusão entre as noções de governança e governabilidade por meio do conceito de "capacidade governativa", entendida aqui como a capacidade do estado em produzir políticas públicas que resolvam os problemas da sociedade. Segundo esta proposta de fusão, os dois conceitos (governabilidade e governança) referem-se a uma única e mesma questão: a questão funcionalista da performance do sistema político em processar as pressões oriundas tanto do ambiente social externo (inputs) como do próprio sistema político (wihtinputs). 
Mesmo que implicitamente, esta concepção funcionalista também está presente na definição que o conceito de governança assume nos diagnósticos e terapias sobre a crise do estado nos anos 1980 e 1990. Para Bresser Pereira (1997, p. 40), principal formulador dos diagnósticos e terapias sobre a crise do estado brasileiro na década de 1990, governança refere-se às condições financeiras e administrativas que o estado precisa reunir para transformar em realidade as decisões que toma. Neste sentido, tanto a crise fiscal do estado como sua incapacidade de produzir e implementar políticas públicas devem ser concebidas como parte essencial da crise de governança dos sistemas políticos contemporâneos.

Para Bresser Pereira, esta crise de governança seria um problema específico do modelo de administração burocrática, tal como definido por Max Weber, e sua superação passaria pela reforma do estado em direção ao "modelo gerencial" (New Public Management). Em seu diagnóstico, o modelo weberiano, por muito tempo pensado como sinônimo de eficiência e "bom governo", aparece como definido pelo formalismo cego (confirmando a previsão do próprio Weber sobre a dominação da "racionalidade formal" nas organizações modernas), pelo centralismo e por sua crescente incompatibilidade com a democracia. Em síntese: a administração burocrática contemporânea contrapõe-se às práticas do "bom governo" (governança), sendo a principal causa da crise do estado brasileiro. Por contraste, a administração pública gerencial, como consta no Plano Diretor da Reforma do Estado, de 1995, é concebida como a mais afinada com a governança contemporânea, promovendo a ênfase no resultado (na "racionalidade material" para usar novamente Weber), e não tanto no formalismo dos procedimentos, a descentralização das atribuições administrativas e "uma participação mais direta da sociedade na gestão pública” (Bresser Pereira, 1997, p. 41).

Neste quadro, embora a crise fiscal seja o principal agravante conjuntural, a crise de governança (a falta de "bom governo") é percebida como estando estruturalmente ligada à incapacidade gerencial do estado em fazer funcionar as políticas públicas. Daí que o ajuste fiscal seja percebido apenas como etapa inicial de uma reforma mais ampla do aparelho do estado visando recuperar sua capacidade gerencial: "Em síntese, a governança será alcançada e a reforma do estado será bem sucedida quando o estado se tornar mais forte embora menor" (Bresser Pereira, 1997, p. 42).

Esta concepção sobre a crise de governança e a reforma do estado, mesmo concebendo que a qualidade de administração pública (governança) está intimamente ligada à prestação de contas dos governos aos eleitores, adere, em parte, ao diagnóstico da sobrecarga de demandas que o pensamento 
liberal-conservador utiliza para explicar a crise de governabilidade nos países do Atlântico Norte. Este diagnóstico da sobrecarga de demandas implica na recusa da noção de responsiviness (responsividade) como elemento chave da governança: o "bom governo" pode, em medida significativa, dispensar o compromisso com a consecução de metas coletivas por meio de políticas públicas voltadas para atender as preferências dos cidadãos legitimadas pelo procedimento democrático. Ou seja, a apregoada afinidade da administração pública gerencial com a participação mais direta da sociedade nas decisões do estado não implica, paradoxalmente, em maior compromisso com as metas coletivas formuladas na inter-relação da política com os diversos grupos e setores sociais. Nesse sentido, o "bom governo", embora democrático, deve, por assim dizer, ser protegido da sobrecarga de demandas sociais que a democracia pode representar.

Contra o diagnóstico e a terapia propostos por Bresser Pereira, norteadoras dos dois governos de Fernando Henrique Cardoso, Eli Diniz (2013) vai desenvolver uma reflexão sobre o conceito de governança com o objetivo de reabilitar o compromisso com a realização de metas coletivas e preferências dos cidadãos (responsiviness) enquanto uma componente chave do "bom governo". Neste sentido, governança engloba necessariamente duas características que balizam a relação entre estado e sociedade, qual seja, (1) a capacidade estatal de penetrar na sociedade e implementar logisticamente suas decisões e (2), em forte relação com esta primeira característica, sua capacidade de realizar metas coletivas e responder às preferências dos cidadãos por meio das políticas públicas postas em prática (responsiviness). Em suas próprias palavras:

Como utilizo o conceito, refiro-me às formas de gestão caracterizadas pela capacidade de construir instâncias de interlocução com a sociedade, voltadas para definir as prioridades da agenda pública, abrindo espaço para a consecução das metas coletivas e a sustentação política das decisões tomadas (Diniz, 2013, p. 17).

Assim, a crise de governança não resulta apenas da incapacidade do estado de gerir e implementar políticas públicas, mas também de sua incapacidade de ser responsivo em relação às preferências dos cidadãos e às metas coletivas formuladas no jogo político. A reforma do estado da década de 1990, idealizada por Bresser Pereira como uma reforma que deveria superar os impasses da administração burocrática por meio do modelo gerencial, teria, segundo Diniz, priorizado quase que de forma exclusiva a dimensão fiscal da crise, negligenciando tanto o aspecto mais propriamente administrativo, 
ou seja, a capacidade do estado de "penetrar" na sociedade e implementar políticas públicas, como também o aspecto normativo da responsividade face às metas coletivas e às preferências dos cidadãos. Na prática, a reforma gerencialista da década de 1990, orientada equivocadamente pelo diagnóstico de que o modelo burocrático é parte do problema e não da solução, ao invés de fortalecer, acabou por debilitar ainda mais a capacidade administrativa do estado, reduzindo seu poder de "penetração" e implementação de políticas na sociedade. Nesse sentido, a redução do tamanho do estado, pelo menos no que tange a seu braço administrativo, ao invés de ser parte da solução, acabando se tornando parte do problema. Além disso, do ponto de vista das metas coletivas, o estado, já debilitado pela crise fiscal e pela redução de sua capacidade administrativa, pouco teria avançado em sua capacidade de atendê-las, delegando cada vez mais ao "terceiro setor", à "sociedade civil" e ao "mercado", a responsabilidade por coordenar o desenvolvimento social e econômico.

A terapia para a crise de governança não passa, portanto, pela superação da administração burocrática, mas sim pela sua reconstrução, uma vez que, entre nós, a burocracia estatal sempre foi fraca e impedida de desenvolver suas virtualidades, especialmente a capacidade de funcionar como aparato implementador do estado e das decisões coletivamente vinculantes. Ao invés de fazer a transição para o modelo gerencial, deveríamos, a exemplo do segundo governo Lula, apostar no reforço, na profissionalização e na ampliação da burocracia estatal, por um lado, e no aumento da responsividade do estado em relação às demandas e metas dos diversos grupos, classes e setores da sociedade, por outro lado.

\section{Governabilidade, governança e a complexidade do sistema político}

Como vimos acima, o conceito de governança, em que pese suas diferentes definições e significados, tem sido empregado para identificar e analisar as condições de emergência e funcionamento do "bom governo", ou seja, do governo democrático. Seu sentido histórico e social específico reside em marcar uma ruptura com a concepção etapista da "teoria da modernização", segundo a qual a democracia, assim como os direitos de cidadania, seriam decorrência automática do desenvolvimento econômico. No lugar desta concepção, o conceito de governança coloca no centro da questão a busca por formas institucionais especificamente políticas capazes de superar formações culturais clientelistas e particularistas que resultam na captura do estado por grupos de interesse e logo na obstrução da democracia. Portanto, é um conceito 
ao mesmo tempo analítico e normativo: serve para analisar as condições fáticas necessárias para se alcançar um estado de coisas percebido como uma norma da vida política moderna, a realização do governo democrático enquanto valor. $\mathrm{O}$ foco, porém, como se pode notar com facilidade, não é a relação formal entre governantes eleitos e governados eleitores, mas antes a qualidade da interação entre o governo e as organizações e grupos da sociedade civil (Boschi, 1999; Diniz, 2013). Nossa tese aqui é a seguinte: se existe algum consenso semântico em relação à noção de governança, este reside na tentativa de vislumbrar a superação do clientelismo e da captura do estado por parte de interesses particularistas, ou seja, na tentativa de analisar as condições de normatização das relações de poder informais que se estabelecem entre o estado o setor organizado do público de cidadãos, aí incluídos deste os sindicatos até as organizações e os lobbies.

O poder formal que o cidadão transfere pelo voto ao governante é, por definição, normatizado, já que expressa a própria "constitucionalização do poder". É precisamente este processo de "constitucionalização do poder" (Neves, 2008, p. 481) que resulta na formação de direitos políticos igualitários a serem exercidos segundo procedimentos eleitorais juridicamente controlados - como expressão da noção de soberania popular, concebida como fonte última de legitimação do poder na sociedade moderna. Na medida em que o acesso ao e o exercício do poder são regulados por procedimentos jurídicos destinados a garantir tanto a expressão da vontade popular como o uso constitucional do poder, espera-se neutralizar a influência direta do poder social sobre o poder político. Ou seja, a constitucionalização do poder deve - trata-se de expectativas normativas! - assegurar o acesso (ainda que potencial) de todos ao poder político.

Já o poder informal não é alcançado pela normatização constitucional, estabelecendo-se como um espaço que contrasta com a igualdade política normativamente esperada no espaço do poder formal. Trata-se de um circuito de poder que tornou-se parte do dia a dia dos sistemas políticos modernos e no qual,

[...] a política não pode funcionar sem as orientações da administração. Assim como o público torna-se dependente da pré-seleção de pessoas e programas dentro da política e a administração passa a depender, na medida em que se expande para campos de forças mais complexos, da atuação voluntária do público, sendo obrigada a concedê-lo alguma influência (Luhmann, 1981, p. 164). 
As relações de poder informais visadas pelo conceito de governança referem-se especialmente aos vínculos seletivos e particularistas que se criam entre a administração e setores do público de cidadãos, sobretudo setores bem organizados. Como as organizações de interesse (as quais nem sempre se apresentem enquanto tal) são o meio mais importante de exercício do poder informal sobre a administração, o público, no espaço do poder informal, acaba se segmentando entre um setor organizado e outro setor não organizado. Isto, por sua vez, como a literatura sobre corporativismo e cidadania tem demonstrado para o caso brasileiro, resulta em enormes e estáveis assimetrias de poder, as quais, ao serem replicadas e reforçadas nas chances de influenciar a produção de decisões coletivamente vinculantes, podem até mesmo levar a uma exclusão política estável do segmento pouco ou nada organizado do público de cidadãos.

O espaço do poder informal ganha mais importância sempre quando a relação entre a administração e o público, especialmente seu segmento organizado, adquire mais autonomia em relação às decisões políticas juridicamente controladas do parlamento e do Executivo. O crescimento e o adensamento das estruturas organizacionais envolvendo a administração e o público, incentivados pela expansão do estado de bem-estar social, elevam a complexidade das situações de decisão com as quais a administração se vê diariamente confrontada em função de suas relações informais com o público. Em geral, isto faz com que a administração torne-se cada vez mais dependente da cooperação dos segmentos organizados do público, e do próprio mercado. Isto porque estes segmentos possuem uma margem de atuação e influência sobre a implementação de políticas públicas que não se deixa controlar pela cadeia de mando estatal juridicamente fixada, ou seja, pelo poder constitucionalizado e pelos programas decisórios oficiais:

Segundo a imagem oficial, a administração toma decisões e as implementa independentemente do público afetado. A questão seria apenas o controle jurídico da decisão e de sua observância, ou seja, se apresenta como um problema do estado de direito e da vigilância de sua execução [...]. Na medida em que o estado de bem-estar social vai se desenvolvendo, a administração, por razões políticas, é cada vez mais incumbida de programas cuja execução depende da cooperação do público. Esta dependência, por sua vez, não pode ser mais controlada pelo direito ou por obrigações jurídicas; e também nem sempre está afinada com os interesses daqueles de cuja atuação conjunta depende a administração. Esta dependência refere-se mais a parceiros organizados com os quais se vai lidar novamente em outras constelações do que a indivíduos dotados de direitos 
subjetivos [...]. Na prática, isto cria uma complexa articulação de interesses à margem da legalidade e até mesmo para além de seus limites. Aquele de cuja cooperação depende a administração pode sempre exigir uma contrapartida (Luhmann, 2012, p. 260-261).

Neste contexto, a oscilação entre partidos e grupos políticos no espaço do poder formal e constitucionalmente normatizado, por meio de eleições periódicas, pode conviver com um espaço de poder informal mais ou menos rígido, no qual determinados setores, em geral os de maior poder econômico e capacidade organizativa (o "dinheiro organizado" do mundo das finanças certamente é o exemplo paradigmático), ao reunirem mais meios para sancionar negativamente a atuação da administração pública, conseguem controlar as melhores chances de influência sobre esta. O tipo extremo seriam os segmentos cujo volume de meios de sanção e poder sobre a administração os permite dissuadir qualquer resistência por parte desta, assim como todo tipo de concorrência por parte dos outros setores do público, organizados ou não.

Na prática, isto pode levar a uma quase fusão semântica dos interesses específicos destes setores altamente organizados e poderosos do público com o interesse público. E mais uma vez o mundo das finanças é o exemplo paradigmático. Desta forma, podemos dizer que as tentativas de normatização das relações de poder informais ensejadas pelo conceito de governança, pelo menos quando se restringem a exigir do estado mais interlocução com a sociedade sem, no entanto, problematizar as gigantescas assimetrias de poder escamoteadas por conceitos vagos e excessivamente ideológicos como o de "sociedade civil", são uma forma de transformar necessidade em virtude. Ou de transformar em norma aquilo que a realidade já impõe: não se trata, a rigor, de o estado decidir por mais interlocução com a sociedade civil, pois, na prática, seu braço administrativo já está profundamente embutido em relações informais de poder com determinados setores desta "sociedade civil".

Nesta acepção um tanto quanto analiticamente "ingênua" (embora, do ponto vista político, não haja nada de ingênuo em encobrir relações de poder) do conceito de governança, as dificuldades do estado em implementar decisões coletivamente vinculantes sem prescindir da cooperação "voluntária" de determinados segmentos organizados do público de cidadãos são ressignificadas como algo essencialmente positivo, não raro sob o rótulo de "participação da sociedade civil".

Desta forma, a fraqueza da política formal - isto é, da política construída sob a base da legitimidade dos procedimentos eleitorais e democráticos - em fazer valer suas decisões coletivamente vinculantes diante de setores sociais que, segundo a normatividade inerente à noção de vontade popular aferida 
pelos procedimentos acima referidos, não deveriam ter nenhum poder "mais poderoso" do que aquele emanado do povo nas urnas, é transformada em uma virtude, no sentido de maior abertura e interlocução com a "sociedade civil".

Podemos dizer que, se o conceito de governabilidade diagnostica a crise do estado em dirigir processos e esferas sociais autonomizadas como caminho necessário para implementar políticas públicas e atender demandas sociais, crise está que obriga faticamente o estado a aceitar uma "governabilidade partilhada" com os setores organizados e poderosos da sociedade, o conceito de governança, quando parte de uma concepção homogênea de "sociedade civil", busca transformar este constrangimento estrutural em modelo normativo. O "bom governo", no que tange às relações informais de poder entre a administração pública e setores organizados da sociedade, seria aquele que não busca isolar a administração destes setores, permitindo uma participação mais direta deles nas decisões governamentais, ficando em segundo plano tanto as implicações desta participação altamente seletiva para a soberania popular e o poder formal dela resultante como também o componente da responsividade do governo em relação às metas e preferências dos cidadãos.

\section{Considerações finais}

A disputa semântica em torno do conceito de governança, tal vimos existir entre as concepções defendidas por Bresser Pereira e Eli Diniz, articula, a nosso ver, diferentes sentidos para o desiderato de regular normativamente as relações entre estado e organizações da sociedade. Neste sentido, o modelo gerencialista que Bresser Pereira defende como o mais afinado com o "bom governo" representa a estratégia de normatização apresentada nos parágrafos anteriores, a qual consiste em elevar ao status de "dever ser" à "governabilidade partilhada" entre a administração pública e "sociedade civil", sendo secundárias as assimetrias de poder existentes nesta. Segundo Eli Diniz, na prática esta vertente do conceito resulta na consagração semântico-normativa dos interesses financeiros, cujo poder e capacidade organizativa, especialmente seu protagonismo nos meios de comunicação de massa, permitiram transformar o imperativo do rigor fiscal em uma verdadeira salvaguarda jurídica e simbólica destes interesses. A exortada abertura do estado à "sociedade civil" adquire aqui o caráter de uma chancela que o poder formal é obrigado a criar para o poder informal dos agentes financeiros, cujo protagonismo vai de encontro à consideração de outros interesses e demandas no espaço informal do poder.

Em contraste com esta concepção, que provavelmente o indivíduo Bresser Pereira nunca sustentou explicitamente, Eli Diniz propõe uma definição para o conceito de governança cuja dimensão normativa coloca a 
ênfase na variedade e na diversidade das demandas e interesses que encontram espaço na relação entre estado e "sociedade civil". Ao invés de exigir que o estado simplesmente se "abra" para a sociedade civil, consagrando as relações de poder nela existentes, exige-se que o estado desempenhe um papel ativo neste processo, reestruturando as relações da sociedade civil e induzindo a criação de capacidade organizativa em setores nos quais esta capacidade não surge "espontaneamente", ou seja, sem o poder do estado.

Desde a "era Vargas", segundo esta segunda vertente da noção de governança, houve no Brasil um processo de ampliação das possibilidades de participação no espaço das relações informais de poder entre o estado e setores da sociedade. O assim chamado "corporativismo de estado", desde então a principal forma de mediação entre interesses privados e públicos, permitiu a inclusão de setores empresariais e trabalhistas nos espaços de poder abertos pelo Executivo enquanto uma dimensão paralela à representação formal de interesses no legislativo. Embora as organizações patronais tivessem mais influência sobre o processo de construção de decisões coletivamente vinculantes (Boschi, 2012, p. 180), não se pode ignorar o enorme avanço que foi o modelo varguista em termos da inclusão dos setores operários mais organizados, ainda que esta inclusão fosse seletiva. Ou seja, o corporativismo não foi apenas uma forma de controle e cooptação política das classes trabalhadoras; foi também um processo de construção da capacidade organizativa e política desta classe, pois "por meio da representação de interesses no processo político, as classes sociais foram mobilizadas e organizadas" (Boschi, 2012, p. 181). Esta inclusão da classe trabalhadora industrial no espaço informal de poder que vincula estado e "sociedade civil" estabeleceu forte correlação com a positivação de direitos sociais e trabalhistas, os quais, em conformidade com o caráter seletivo desta inclusão, foram asseguradas apenas àquelas, cuja posição no mercado de trabalho era reconhecida formalmente pelo estado como profissão.

Que este modelo favoreceu a criação de capacidade organizativa de setores da "sociedade civil" fica claro quando os sindicatos criados na "era Vargas", como ocorre já na década de 1950, demonstram uma capacidade de conflito não mais domesticável pelo Executivo e suas relações informais com estas organizações trabalhistas. O modelo de "bom governo" defendido por Diniz, em contraste com o modelo gerencialista, consiste em aprofundar e aperfeiçoar o protagonismo do estado na reestruturação da sociedade como forma de ampliar o círculo de segmentos sociais incluídos no espaço informal de poder. Ao invés de superar a "era Vargas", retirando do estado aquele protagonismo sob a crença de com isso dar mais autonomia à "sociedade civil", 
o caminho seria reatualizar o estado nacional-desenvolvimentista, sobretudo por meio da ampliação do leque de atores incluídos no espaço informal de poder.

Cabe ressaltar duas importantes implicações desta concepção de governança defendida por Diniz. A primeira diz respeito à relação entre governança e governabilidade. Na medida em que o "bom governo", no que tange às relações entre estado e "sociedade civil", se baseia na capacidade de incluir e agregar diversos interesses, estabelece-se uma relação de reforço mútuo com a governabilidade: a inclusão e a agregação de interesses diversos aumentam a legitimidade do governo e, portanto, a governabilidade do país, ou seja, a capacidade do estado de intervir em processos e esferas sociais a fim de implementar políticas públicas (Reis, 1994). A segunda diz respeito ao significado da noção de "empoderamento" tanto para a governança como para a governabilidade. Na medida em que o "empoderamento" de setores dotados de pouca ou nenhuma capacidade organizacional e pressão sobre o estado favorece a inclusão e a agregação de novos interesses e demandas sociais (governança), promove também a legitimidade e a governabilidade do poder público.

O protagonismo estatal na organização dos interesses de grupos e classes sociais costuma ser visto com desconfiança na teoria política e social. À direita e à esquerda vige uma certa crença e esperança não tematizadas na capacidade de "organização espontânea" dos interesses. Em geral, o surgimento de organização de interesses é deduzido da mera diferenciação e aglutinação espontânea de interesses sociais. Nesta visão, a relação entre estado e sociedade é reduzida a um jogo de soma zero, no qual mais força e autonomia de um polo da relação levaria a debilidade e perda de autonomia do outro polo. Estado que organiza interesses sociais produziria sempre uma sociedade civil débil e acostumada à tutela. No entanto, a pesquisa social e histórica tem demonstrado que a ação coletiva depende de uma gama de condições, pressupostos e incentivos, não tendo, portanto, nada de "espontânea". Olson (1965), por exemplo, tornou evidente a improbabilidade da organização de interesses sociais, a qual afeta especialmente aqueles interesses que não podem basear sua cooperação em convergências e consensos do presente, mas apenas em convergências e consensos projetados no futuro. A tarefa organizativa é muitas vezes produzir a própria convergência e consenso. As preferências, especialmente em ambientes sociais instáveis, não podem ser determinadas com clareza. A iniciativa organizacional do estado sobre os interesses sociais, ao invés de minar, pode favorecer sua autonomia e capacidade de influência política, promovendo, portanto, o pluralismo. Neste sentido, 
o protagonismo estatal pode contribuir para aumentar a probabilidade da dinâmica inicialmente improvável de uma configuração pluralista de interesses com capacidade organização e ação políticas; ainda que no começo, como a organização dos trabalhadores na "Era Vargas" demonstra, esta organização seja uma obra tutelada pelo estado. Estudos comparativos (Czada, 1991) sugerem que este protagonismo estatal na organização de interesses foi um fator importante, senão decisivo, no desenvolvimento social e econômico de países como Estados Unidos e Alemanha, não sendo particularidade de países "em desenvolvimento". Nestes dois países, por exemplo, organizações de interesse no setor agrário da economia foram, em sua maioria, criadas a partir de iniciativas do estado e de dirigentes e funcionários públicos do setor. Para o estado, estas organizações realizam tarefas político-administrativas que, dada sua complexidade, não podem ficar a cargo somente da administração. Além disso, a abertura da burocracia estatal para os interesses socais também pode contribuir para o aperfeiçoamento do saber técnico que as organizações burocráticas dispõem sobre os diferentes setores de atuação estatal. ${ }^{4}$ Para os interesses setoriais, servem para dar prospecção e promovê-los. $\mathrm{O}$ foco deve estar nas redes especializadas e setoriais de organizações que constroem a relação entre estado e sociedade (Czada, 1991, p. 153)

O quadro teórico desenvolvido neste texto, valendo-se da diferença entre poder formal e poder informal, culmina na tese de que a tentativa de normatizar as relações de poder informais que se estabelecem entre o estado o setor organizado do público de cidadãos é o consenso semântico em torno do qual gravitam as diferentes concepções da ideia de governança. Uma diferença importante, no entanto, é aquela que se estabelece entre aqueles que colocam o acento normativo na simples "abertura" do estado à "sociedade civil" e aqueles que prescrevem um papel ativo do estado no sentido de reestruturar as relações e assimetrias de poder na sociedade.

\footnotetext{
${ }^{4}$ A sociologia da burocracia de Weber é, muitas vezes, erroneamente interpretada como uma sociologia da eficiência absoluta do insulamento burocrático. Embora a ênfase no insulamento seja predominante, Weber não deixou de perceber que a abertura da administração pública para a ambiente de interesses sociais contribui para o aumento do conhecimento técnico e consequentemente do próprio poder da organização burocrática do estado: "Na esfera da economia, o saber técnico da burocracia só é inferior ao saber dos interesses econômicos privados. Isto porque, nesta esfera, o saber técnico sobre economia é uma questão de sobrevivência direta" (Weber, 1972, p. 574). Para ele, o desenvolvimento de canais de abertura com os interesses sociais, "os quais buscam colocar o conhecimento de causa dos interesses a serviço da administração racional de funcionários qualificados, possui certamente um futuro significativo e aumenta ainda mais o poder da burocracia (Weber, 1972, p. 574).
} 


\section{Referências}

BOSCHI, Renato Raul. Descentralização, clientelismo e capital social na governança urbana: comparando Belo Horizonte e Salvador. Dados, v. 42, n. 4, p. 655-690, 1999.

BOSCHI, Renato Raul. Interessengruppierungen, der Staat und die Beziehungrn zwischen den Staatsgewalten in Brasilien. In: Dana de La Fontaine; Thomas Stehnken (orgs.). Das politische System Brasiliens. Wiesbaden: VS Verlag, 2012. p. 175-192.

BRESSER PEREIRA, Luiz Carlos. A reforma do estado dos anos 90: lógica e mecanismos de controle. Cadernos Mare da Reforma do Estado, v. 1, n. 1, p. 7-59, 1997.

CZADA, Roland. Regierung und Verwaltung als Organisation gesellschaftlicher Interessen. In: Hans-Hermann Hartwich; Göttrik Wewer (orgs.). Regieren in der Bundesrepublik III: Systemsteuerung und „Staatskunst“. Opladen: WS Verlag, 1991. p. 151-173.

DINIZ, Eli. Desenvolvimento e estado desenvolvimentista: tensões e desafios da construção de um novo modelo para o Brasil do século XXI. Revista de Sociologia Política, v. 21, n. 47, p. 9-20, 2013.

GADAMER, Hans-Georg. Rethorik, Hermeneutik und Ideologiekritik: Metakritische Eröretungen zu "Wahrheit und Methode". In: Karl-Otto Apel et al. (orgs.). Hermeneutik und Ideologiekritik. Frankfurt am Main: Suhrkamp, 1971. p. 57-82.

GRÜN, Roberto. A dominação financeira no Brasil contemporâneo. Tempo Social, v. 25 , n. 1 , p. 179-213, 2013

HABERMAS, Jürgen. A crise de legitimação no capitalismo tardio. 2. ed. Rio de Janeiro: Tempo Brasileiro, 2002.

HUDSON, John; LOWE, Stuart. Understanding the policy process: analyzing welfare policy and practice. Bristol: The Policy Press, 2004.

HUNTINGTON, Samuel et al. The crisis of democracy: report on the governability of democracies to the trilateral commission. New York: New York University Press, 1975.

LUHMANN, Niklas. Machtkreislauf und Recht in Demokratien. Zeitschrift für Rechtssoziologie, n. 2, p. 158-167, 1981.

LUHMANN, Niklas. Die Politik der Gesellschaft. Frankfurt am Main: Suhrkamp, 2012.

MINISTÉRIO da Administração Federal e Reforma do Estado. Plano Diretor da Reforma do Aparelho do Estado. Brasília: Imprensa Nacional, novembro 1995. Plano aprovado pela Câmara da Reforma do Estado da Presidência da República em setembro de 1995.

NEVES, Marcelo. Verfassung und Öffentlichkeit: zwischen Systemdifferenzierung, Inklusion und Anerkennung. Der Staat. Zeitschrift für Staatslehre und Verfassungsgeschichte deutsches und europäisches öffentliches Rechts, v. 47, n. 4, p. 477-509, 2008.

O’ CONNOR, James. A crise do estado capitalista. Rio de Janeiro: Paz e Terra, 1997. 
OLSON, Mancur. The logic of collective action. Cambridge: Harvard University Press, 1965.

REIS, Fábio Wanderley. Governabilidade e instituições políticas. In: João Paulo dos Reis Velloso (org.). Governabilidade, sistema político e violência urbana. Rio de Janeiro: José Olympio, 1994. p. 387-417.

SANTOS, Maria Helena de Castro. Governabilidade, governança e democracia: criação de capacidade governativa e relações Executivo-Legislativo no Brasil pósconstituinte. Dados, v. 40, n. 3, $1997<10.1590 /$ S0011-52581997000300003>.

SCHNEIDER, Wolfgang Ludwig. Systemtheorie, hermeneutische Tradition und die Theorie sozialer Differenzierung. In: John René et al. (org.). Die Methodologien des Systems: wie kommt man zum Fall und wie dahinter? Wiesbaden: VS Verlag, 2010. p. 203-224.

WEBER, Max. Wirtschaft und Gesellschaft. Grundriss der verstehenden Soziologie. 5. ed. Tübingen: Mohr-Siebeck, 1972.

Recebido em: 15 dez. 2014

Aprovado em: 28 out. 2015

Autor correspondente:

Roberto Dutra Torres

Av. Alberto Lamego, 2000 - Parque Califórnia

28013-600 Campos dos Goytacazes, RJ, Brasil 